tee; updated 2005 Mar 31. Available: http //gacguidelines.ca/article.pl?sid=02/07/03/20172 36 (accessed 2005 Apr 28).

Competing interests: None declared.

DOI:10.1503/cmaj.1050069

\section{[The author responds:]}

$\mathrm{I}$ $t$ is not a matter of misquoting, but it may be selective quoting. Dave Davis is correct that the GAC "guideline note" mentions the overuse of antibiotics for acute otitis media. But the recommendations themselves ${ }^{2}$ advise that symptomatic patients be treated with antibiotics; only for asymptomatic patients can antibiotics be deferred. My plea $^{3}$ was to be even more restrictive.

\section{Roger A.M.J. Damoiseaux \\ General Practitioner \\ General Practice "de Hof van Blom" \\ Hattem, The Netherlands}

\section{References}

1. Otitis media: antibiotic therapy. Guideline notes. Toronto: Guidelines Advisory Committee; updated 2005 Mar 31. Available: http //gacguidelines.ca/article.pl?sid=02/07/03/2017236 (accessed 2005 Jun 21).

2. Linsk R, Blackwood A, Cooke J, Harrison V, Lesperance M, Hildebrandt HM. University of Michigan Health System. Guidelines for clinical care. Otitis media. Ann Arbor (MI): Regents of the University of Michigan; updated 2002 May. Available: http://cme.med.umich.edu/pdf/guideline /om.pdf (accessed 2005 Jun 21).

3. Damoiseaux RAMJ. Antibiotic treatment for acute otitis media: time to think again [commentary]. CMA7 2005;172(5):657-8.

Competing interests: None declared.

DOI:10.1503/cmaj.1050106

\section{HRT and antidepressants}

$\mathrm{R}$ oger McIntyre and associates ${ }^{1}$ discuss reciprocal relationships between hormone replacement therapy (HRT) and antidepressant treatment. Although some women experience significant mood changes related to changes in estrogen levels at menopause, I believe there is another obvious explanation for the increase in prescriptions for selective serotonin reuptake inhibitors (SSRIs) after publication of the Women's Health Initiative (WHI) trial. ${ }^{2}$

Hot flashes occur in $65 \%-75 \%$ of women during natural or induced menopause. ${ }^{3}$ Many women discontinued their hormone therapy because of the WHI results but continued to experience significant symptoms and sought medicinal help from their physicians. The only medications with scientific proof of efficacy, other than estrogen and progestins, are SSRIs, clonidine and, more recently, gabapentin..$^{3-7}$

As demonstrated by Loprinzi and colleagues, ${ }^{7}$ breast cancer patients with depression reported a reduction in hot flashes when taking SSRIs. Subsequently, other SSRIs were shown to have similar beneficial effects. However, SSRIs are much less effective in this regard than HRT (which is more than $85 \%$ effective). ${ }^{3}$

\section{Wendy L. Wolfman \\ Director \\ Menopause Unit \\ Mount Sinai Hospital \\ Toronto, Ont.}

\section{References}

1. McIntyre RS, Konarski JZ, Grigoriadis S, Fan NC, Mancini DA, Fulton KA, et al. Hormone replacement therapy and antidepressant prescription patterns: a reciprocal relationship [editorial]. CMA7 2005;172(1):57-9.

2. Rossouw JAE, Anderson GL, Prentice RL, LaCroix AZ, Kooperberg C, Stefanick ML, et al. Risks and benefits of estrogen plus progestin in healthy postmenopausal women: principal results from the Women's Health Initiative randomized controlled trial. 7AMA 2002;288:321-33.

3. North American Menopause Society. Treatment of menopause-associated vasomotor symptoms: position statement of the North American Menopause Society. Menopause 2004;11:11-33.

4. Evans M, Pritts E, Vittinghoff E, McClish K, Morgan KS, Jaffe RB. Management of postmenopausal hot flushes with venlafaxine hydrochloride: a randomized, controlled trial. $O b-$ stet Gynecol 2005;105(1):161-6.

5. Loprinzi CL, Sloan JS, Perez EA, Quella SK, Stella PJ, Mailliard JA, et al. Phase III evaluation of fluoxetine for treatment of hot flashes. $7 \mathrm{Clin}$ Oncol 2002;20:1578-83.

6. Stearns V, Beebe KL, Iyengar M, Dube E. Paroxetine controlled release in the treatment of menopausal hot flashes: a randomized controlled trial. $7 A M A$ 2003;289:2827-34
7. Loprinzi CL, Kugler JW, Sloan JA, Mailliard JA, LaVasseur BI, Barton DL, et al. Venlafaxine in management of hot flashes in survivors of breast cancer: a randomized controlled trial. Lancet 2000;3 36:2059-63.

Competing interests: Dr. Wolfman has received an honorarium from Wyeth for speaking to physicians about issues to do with menopause.

DOI:10.1503/cmaj.1050022

Twas dismayed when I read the com1 mentary by Roger McIntyre and associates $^{1}$ regarding antidepressants and menopause. The final paragraph, advising practitioners to "familiarize themselves with the beneficial effects of serotonergic antidepressants on climacteric symptoms" is essentially a push to prescribe these medications for symptomatic menopausal women.

This suggestion is backed up by one reference, a position statement of the North American Menopause Society. ${ }^{2}$ This article is a literature review (I am unaware of any properly conducted clinical studies on this subject) which in fact recommends other interventions (e.g., lifestyle and dietary supplements) as first-line therapy, with SSRIs coming in later, together with progesterone and gabapentin.

Overall, I believe this commentary is misleading. It encourages physicians to prescribe a potent class of medications for climacteric symptoms without the benefit of any careful clinical studies.

\section{Keith Symon}

Physician

Burnaby, BC

\section{References}

1. McIntyre RS, Konarski JZ, Grigoriadis S, Fan NC, Mancini DA, Fulton KA, et al. Hormone replacement therapy and antidepressant prescription patterns: a reciprocal relationship [editorial]. CMA7 2005;172(1):57-9.

2. North American Menopause Society. Treatmen 